\title{
Spinal cord compression by a rheumatoid nodule
}

\author{
BERNARD FAIRBURN \\ From the Oldchurch Hospital, Romford, Essex
}

SYNOPSIS A case, believed to be unique, is reported of spinal cord compression due to an extradural rheumatoid nodule.

Rheumatoid arthritis is a systemic disease affecting many organs other than joints. Rheumatoid nodules have been described in the heart, larynx, pleura, peritoneum, and vertebrae (Bagenstoss, 1952), spleen, lungs, oesophagus, skeletal muscle, and peripheral nerve (Maher, 1954). The central nervous system is rarely affected by this disease except as a result of mechanical compression of the spinal cord due to joint subluxation. A case of compression of the spinal cord by a simple rheumatoid nodule is here described.

\section{CASE REPORT}

A 66 year old widower was admitted to hospital on 11 December 1973. Two years previously he had developed rheumatoid arthritis affecting first his knees and later his hands, feet, elbows, shoulders, and neck. He had been treated by phenylbutazone, benorylate, and prednisone, with only partial control of his disease. He had become increasingly disabled and could walk only with the help of a stick. For two weeks before his admission he had had increasing difficulty in walking and for two days he had been unable to walk at all. Sphincter function was normal.

On examination, he had typical rheumatoid nodules over both elbows, hands, (Fig. 1) the right shoulder, and the left knee. His hands showed ulnar deviation with swelling of the metacarpophalangeal joints. Both knees were painful and swollen. Neck movements were all limited and painful. Examination of the cranial nerves was normal. The hand-grip was weak on both sides but power was normal at other segments of the upper limbs. The tendon reflexes were brisk but sensory function was intact. There was a severe spastic weakness of both lower limbs, worse on the right. The tendon reflexes in both lower limbs were grossly exaggerated with bilateral (Accepted 21 May 1975.) extensor plantar responses. There was sustained clonus at the right ankle. He showed loss of appreciation of pain below D5 dermatome level. Postural sense was severely impaired in both great toes and vibration sense was absent below D5 segmental level.

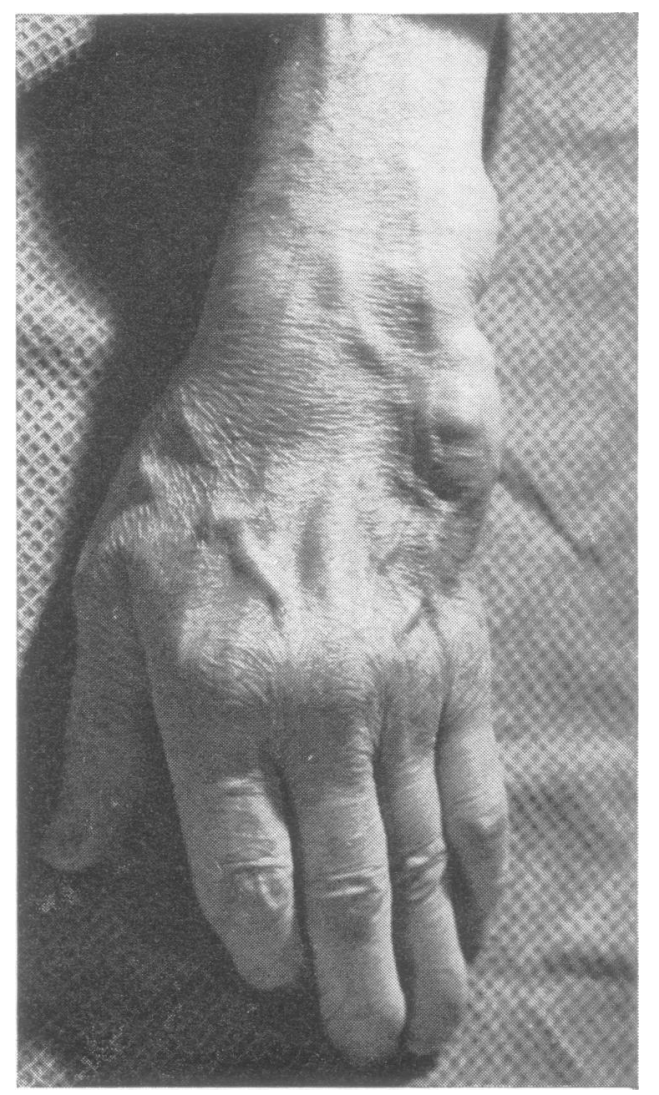

FIG. 1 Typical subcutaneous rheumatoid nodule on left hand. 


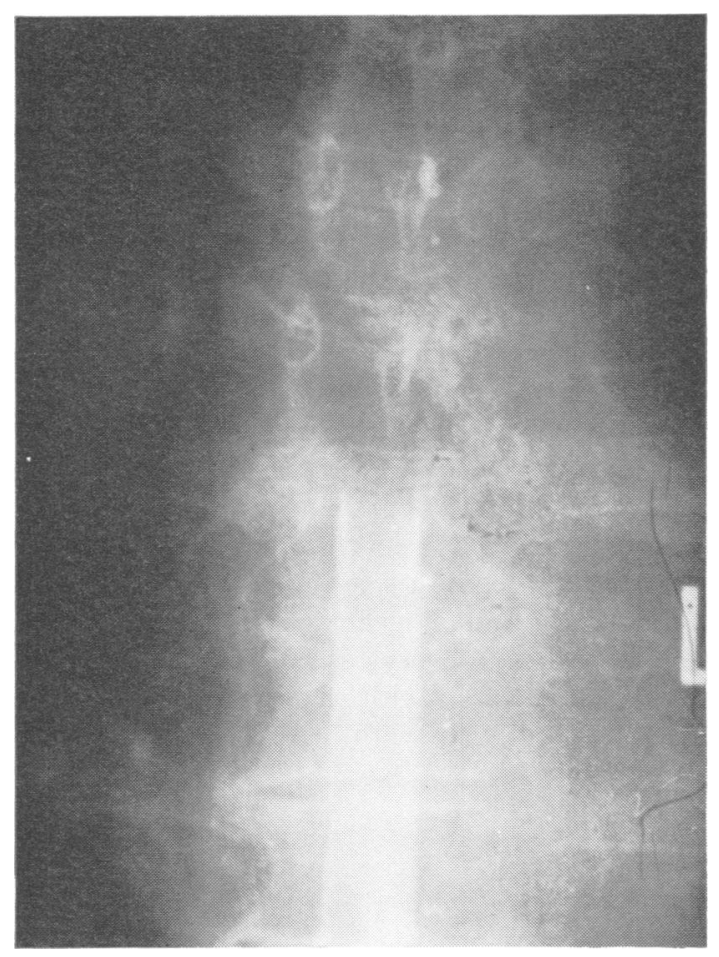

FIG. 2 Lumbar myelogram showing complete block with a rounded lower margin at lower border of D4 vertebra.
INVESTIGATIONS Blood haemoglobin level was 10.7 $\mathrm{g} / \mathrm{dl}$. WBCs $10.700 / \mathrm{mm}^{3}$ (normal differential), the ESR was $91 \mathrm{~mm} / \mathrm{g} / \mathrm{h}$. CSF contained protein 0.52 $\mathrm{g} / \mathrm{l}$ and 2 polymorphs per $\mathrm{mm}^{3}$. Radiography of the cervical spine showed forward displacement of the atlas on the axis by $5 \mathrm{~mm}$. The cervical canal was, however, quite wide at this level. The dorsal spine was normal. Lumbar myelogram showed a complete block with a rounded lower margin at the lower border of D4 vertebra (Fig. 2). A cisternal myelogram showed a complete block with a rounded upper margin at the lower border of D3 vertebra.

OPERATION On 10 January 1974, a laminectomy of D3, 4, and 5 vertebrae was carried out. There was no disease in the paraspinal muscles, the spines, or the laminae. At the level of D4 vertebra, a shiny pinkish-yellow encapsulated cystic swelling was seen on the dorsum of the cord. It measured $2 \mathrm{~cm}$ in length $\times 1 \mathrm{~cm} \times 1 \mathrm{~cm}$. It lay quite free in the extradural space and was completely removed without difficulty, stripping quite easily from the dura mater.

Histological examination (Dr E. J. Atkinson) showed a bilocular hollow mass having a thick fibrous wall lined by chronic inflammatory granulation tissue including large number of plasma cells and epithelioid cells, together with areas of fibrinoid change and occasionally a palisade appearance. Focal calcification was present in the fibrous wall. No bacteria were demonstrated by Gram's stain (Fig. 3). The swelling was considered to be a chronic rheumatoid nodule.

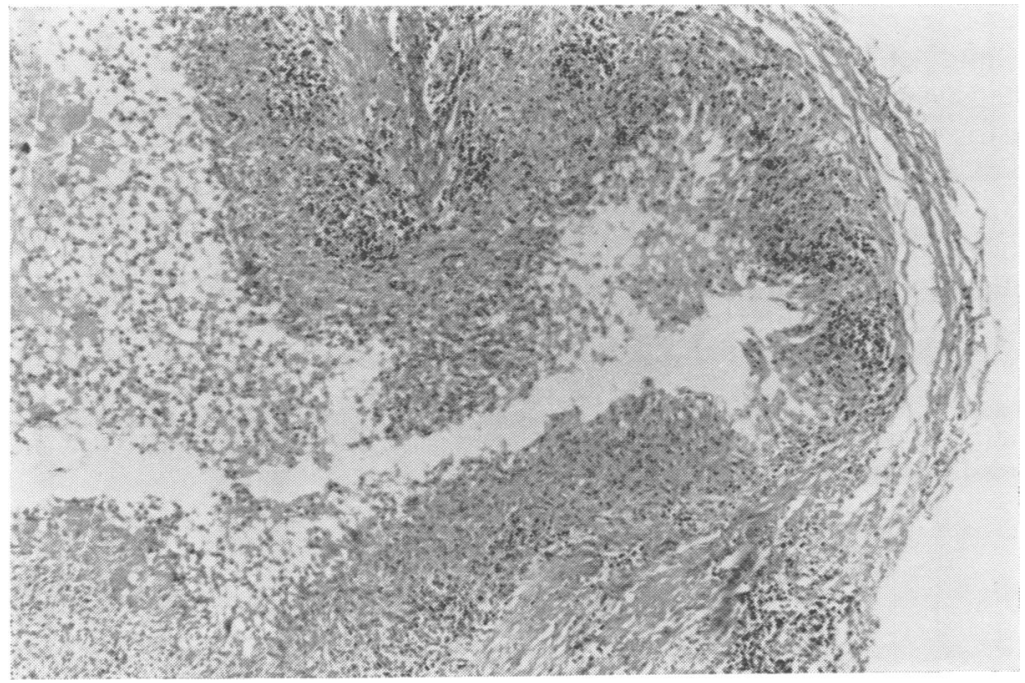

FIG.' 3 Section of excised lesion showing typical appearances of a chronic rheumatoid nodule. Haematoxylin/Van Gieson, $\times 40$. 
PROGRESS There was a steady recovery in the power of the lower limbs. The patient can now walk with elbow crutches. His functional recovery has been hindered by the development of avascular necrosis of the head of the left femur for which a hip replacement is being considered.

\section{DISCUSSION}

Rheumatoid arthritis can affect the nervous system in a number of different ways. Peripheral neuropathy in rheumatoid arthritis was first described by Dudley Hart et al. (1957). This subject was recently reviewed by Heathfield (1973).

Compression of the cervical cord may occur as a result of subluxation of diseased joints either at the atlantoaxial joint (Rana et al., 1973) or at a lower level of the cervical cord (Crellin et al., 1970).

Rheumatoid nodules have been observed in the cranial dura mater and spinal subarachnoid space (Ellman et al., 1954; Maher, 1954; Steiner and Gelbloom, 1959). In all these cases the nodules were unexpected findings at necropsy in patients who had died from advanced rheumatoid arthritis.

Lindquist and McDonnell (1970) described a 52 year old woman who presented with pain in the left lower extremity and a subcutaneous mass in the lumbar region. This proved to be a large rheumatoid cyst, partly subcutaneous and partly extradural, causing compression of the cauda equina from L3 to L5 roots.

Friedman (1970) described a 42 year old man who presented with backache and left sciatica who was found to have an extensive extradural cystic rheumatoid nodule causing compression of the cauda equina from L4 to S2 roots. The lesion had extended outside the vertebral canal and was infiltrating the paravertebral muscles.

The case reported here is therefore the only example of spinal cord compression by a simple rheumatoid nodule confined entirely to the extradural space.

It is interesting to speculate how such a chronic lesion could have caused paraplegia of apparently sudden onset. It is possible that the early signs of neurological involvement may have been masked by the already severe disability due to the patient's advanced rheumatoid arthritis. Signs of minor neurological disorder might have been present for some time before the paraplegia became obvious. Furthermore, it is well known that benign expanding lesions may be tolerated by the nervous system for a long time until a point is reached at which the process of compensation breaks down, when signs of compression may appear quite rapidly.

Before the myelogram, it was thought that the site of this patient's cord compression might be at the atlantoaxial level where there was a pathological degree of subluxation. It is clearly essential that a myelogram should be carried out before surgery in every case of spinal cord compression associated with rheumatoid arthritis in order to establish with certainty the site of compression.

\section{REFERENCES}

Bagenstoss, A. H., Bickel, W. H., and Ward, L. E. (1952). Rheumatoid granulomatous nodules as destructive lesions of vertebrae. Journal of Bone and Joint Surgery, 34A, 601-609.

Crellin, R. Q., MacCabe, J. J., and Hamilton, E. B. D. (1970) Severe subluxation of the cervical spine in rheumatoid arthritis. Journal of Bone and Joint Surgery, 52B, 244-251.

Ellman, P., Cudkowicz, L., and Elwood, J. S. (1954). Widespread serous membrane involvement by rheumatoid nodules. Journal of Clinical Pathology, 7, 239-244.

Friedman, H. (1970). Intraspinal rheumatoid nodule causing nerve root compression. Journal of Neurosurgery, 32, 689-691.

Hart, F. D., Golding, J. R., and MacKenzie, D. H. (1957). Neuropathy in rheumatoid disease. Annals of the Rheumatic Diseases, 16, 471-480.

Heathfield, K. (1973). Neurological complications of the rheumatic diseases. Rheumatology and Rehabilitation, 12, 2-21.

Lindquist, P. R., and McDonnell, D. E. (1970). Rheumatoid cyst causing extradural compression. Journal of Bone and Joint Surgery, 52A, 1235-1240.

Maher, J. A. (1954). Dural nodules in rheumatoid arthritis. Archives of Pathology, 58, 354-359.

Rana, N. A., Hancock, D. O., Taylor, A. R., and Hill, A. G. S. (1973). Atlanto-axial subluxation in rheumatoid arthritis. Journal of Bone and Joint Surgery, 55B, 458-470.

Steiner, J. W., and Gelbloom, A. J. (1959). Intracranial manifestations in two cases of systemic rheumatoid disease. Arthritis and Rheumatism, 2, 537-545. 